\title{
APLIKASI ANALYTICAL HIERARCHY PROCESS (AHP) DALAM PENENTUAN SKALA PRIORITAS PENYELENGGARAAN JALAN DI KECAMATAN CIBINONG KABUPATEN BOGOR
}

\section{Application of Analytical Hierarchy Process (AHP) In Determining Priority Scale Road Operations In District Cibinong Bogor Regency}

\author{
Punti Minesa 1, Hermanto Siregar ${ }^{2}$, Manuwoto ${ }^{3}$ \\ ${ }^{1}$ Kepala Sub Bagian Tata Usaha pada Unit Pelaksana Teknik (UPT) Jalan dan Jembatan Wilayah I Cibinong \\ Dinas Bina Marga dan Pengairan Kabupaten Bogor. Email: kandata08@gmail.com \\ ${ }^{2}$ Guru Besar Ilmu Ekonomi, Departemen Ilmu Ekonomi, Fakultas Ekonomi dan Manajemen \\ Intitut Pertanian Bogor. E-mail: hermansiregar@yahoo.com \\ ${ }^{3}$ Staff Pengajar Sekolah Pascasarjana Intitut Pertanian Bogor. Email: manuwoto@gmail.com
}

\begin{abstract}
Road management activities intended to allow roads to work as it role as supporting the growth of economic. To achieve these objectives, the roads should always be in steady condition. Road management activities should be planed based on the scale of priorities according to the importance of the road, so that allocation of budgeted funds can be effective. Thus the need to review the prioritization of road maintenance in accordance with the need of the community. The method used in this study is Analytical Hierarcy Process with the criteria used are: The function of the services, The aspirations of the people, Political aspirations and Technical approach. Based on the result of AHP, the most decisive criteria in District Cibinong road handling, is the criterion of service functions, in turn, sub criteria transportation route serving and serving terminal / sub-terminals are the two sub criteria that highly prioritized. Furthermore there are four (4) strategies in carrying out road maintenance activities on roads that become priorities, namely: Maintain the road conditions; Strategies to improve the quality of road construction; Strategies to optimize the width of pavement and Strengthening the right of way on roads that do not meet the requirements.
\end{abstract}

Keywords: Road District, Priority Scale, AHP Methode

\begin{abstract}
ABSTRAK
Usaha penyelenggaraan jalan ditujukan agar ruas jalan dapat berfungsi sesuai perannya sebagai penunjang pertumbuhan ekonomi. Untuk mencapai tujuan tersebut diperlukan ruas jalan yang selalu ada dalam kondisi mantap. Kegiatan penyelenggaraan jalan harus disusun berdasarkan skala prioritas sesuai dengan tingkat kepentingan dari ruas jalan, sehingga alokasi dana yang dianggarkan menjadi tepat sasaran. Obyek penelitian meliputi 27 ruas jalan kabupaten di Kecamatan Cibinong, bertujuan untuk menentukan strategi dan program alternatif yang dapat dilaksanakan oleh Pemerintah Kabupaten Bogor dalam menyelenggarakan penanganan jalan. Dalam kondisi keterbatasan dana sulit menentukan prioritas penangannnya. Maka diperlukan prioritas penanganan jalan sesuai dengan kebutuhan masyarakat. Metode yang digunakan adalah metode Analitycal Hierarcy Process dengan kriteria yang digunakan adalah (1) fungsi layanan, (2) aspirasi masyarakat, (3) aspirasi politis dan (4) pendekatan teknis. Berdasarkan hasil AHP, kriteria yang paling menentukan adalah kriteria fungsi layanan, selanjutnya sub kriteria melayani trayek angkutan dan terminal/sub terminal adalah dua sub kriteria yang sangat diprioritaskan. Selanjutnya terdapat 4 (empat) strategi dalam menyelenggarakan kegiatan penanganan jalan, yaitu: (1) Mempertahankan kondisi jalan pada ruas jalan prioritas; (2) Strategi meningkatkan kualitas konstruksi pada ruas jalan prioritas; (3) Strategi mengoptimalkan lebar perkerasan pada ruas jalan prioritas dan (4) membenahi ruang milik jalan (Rumija) pada ruas jalan yang belum memenuhi ketentuan.
\end{abstract}

Kata Kunci: Jalan Kabupaten, Skala Prioritas, Metode AHP 


\section{PENDAHULUAN}

\section{Latar Belakang}

Pemerintah Kabupaten Bogor telah melakukan berbagai usaha untuk melaksanakan otonomi daerah sebaik munngkin, yang salah satunya adalah penanganan infrasturktur jalan dimana Kabupaten Bogor memiliki 458 ruas jalan yang berstatus jalan kabupaten, dengan jumlah panjang $1.748,915 \mathrm{~km}$ yang tersebar di 40 (empat puluh) kecamatan.

Dalam masa pembangunan terdapat ketimpangan anggaran antara usulan dan realisasi penganggaran kegiatan penyelengggaraan jalan yang terjadi disetiap tahunnya. Pada tahun 2011 Pemerintah Daerah Kabupaten Bogor menanggarkan biaya penanganan jalan sebesar Rp. 345.994.685.000 sedangkan usulan dari Rencana Kerja (Renja) Dinas Bina Marga dan Pengairaan Kabupaten Bogor sebesar Rp. 431.543.387.000,- , ini belum termasuk usulan yang bersifat buttom-up dari aspirasi masyarakat secara langsung seperti Musrenbang, Reses dan sebagainya. Pada tahun 2013, usulan kegiatan penyelenggaraan jalan sebesar Rp.2.021.560.959.867 sedangkan alokasi yang didapat adalah sebesar Rp. 740.800.293.000. Hal ini menunjukan bahwa begitu pentingnya skala prioritas dalam menentukan kegiatan penyelenggaraan jalan di Kabupaten Bogor.

Proporsi Anggaran Pendapatan dan Belanja Daerah (APBD) Kabupaten terhadap alokasi anggaran untuk penanganan jalan tiap tahunnya dinilai masih kurang untuk memenuhi kebutuhan penyelenggaraan jalan. Pada Tabel 1.1. dapat dilihat bahwa dari tahun 2009 ke tahun 2014, anggaran untuk Dinas Bina Marga dan Pengairan (DBMP) selalu mengalami peningkatan, sesuai dengan penerimaan APBD Pemerintah Kabupaten Bogor. Pada tahun 2009, anggaran DBMP adalah Rp 320 miliar, pada tahun 2014 mengalami peningkatan hampir tiga kali lipatnya, menjadi Rp 823 miliar. Jika dilihat dari persentase terhadap APBD, anggaran ini meningkat, dari $13,46 \%$ pada tahun 2009 menjadi $16,73 \%$ pada tahun 2014.

Tabel. 1.1. Persentase APBD terhadap Anggaran Penanganan Jalan

\begin{tabular}{cccc}
\hline Tahun & $\begin{array}{c}\text { APBD TOTAL } \\
\text { ( Rp. })\end{array}$ & $\begin{array}{c}\text { APBD DBMP } \\
\text { ( Rp. })\end{array}$ & Persentase \\
\hline 2009 & $2.380 .595 .223 .000,00$ & $320.351 .735 .000,00$ & $13,46 \%$ \\
2010 & $2.785 .105 .931 .000,00$ & $370.045 .884 .000,00$ & $13,29 \%$ \\
2011 & $3.520 .527 .730 .698,00$ & $397.961 .755 .000,00$ & $11,30 \%$ \\
2012 & $4.044 .100 .619 .000,00$ & $607.711 .894 .000,00$ & $15,03 \%$ \\
2013 & $4.504 .277 .319 .000,00$ & $740.800 .293 .000,00$ & $16,45 \%$ \\
2014 & $4.921 .319 .444 .000,00$ & $823.417 .474 .000,00$ & $16,73 \%$ \\
\hline
\end{tabular}

Sumber : BAPPEDA Kabupaten Bogor

Perbandingan nilai anggaran dalam usulan kegiatan penanganan jalan dengan anggaran yang direalisasikan pada tahun 2012 di wilayah-wilayah yang dipandang strategis di Kabupaten Bogor seperti wilayah Cibinong Raya bervariasi, namun tetap di beberapa kecamatan masih timpang antara kegiatan yang diusulkan dengan kegiatan yang direalisasikan. Pada gambar 1.1 dapat terlihat anggaran, baik yang diusulkan maupun yang di realisasikan pada tahun 2012 di Kecamatan Cibinong adalah terbesar dibandingkan dengan kecamatan-kecamatan lain yang bersifat strategis di Kabupaten Bogor. 


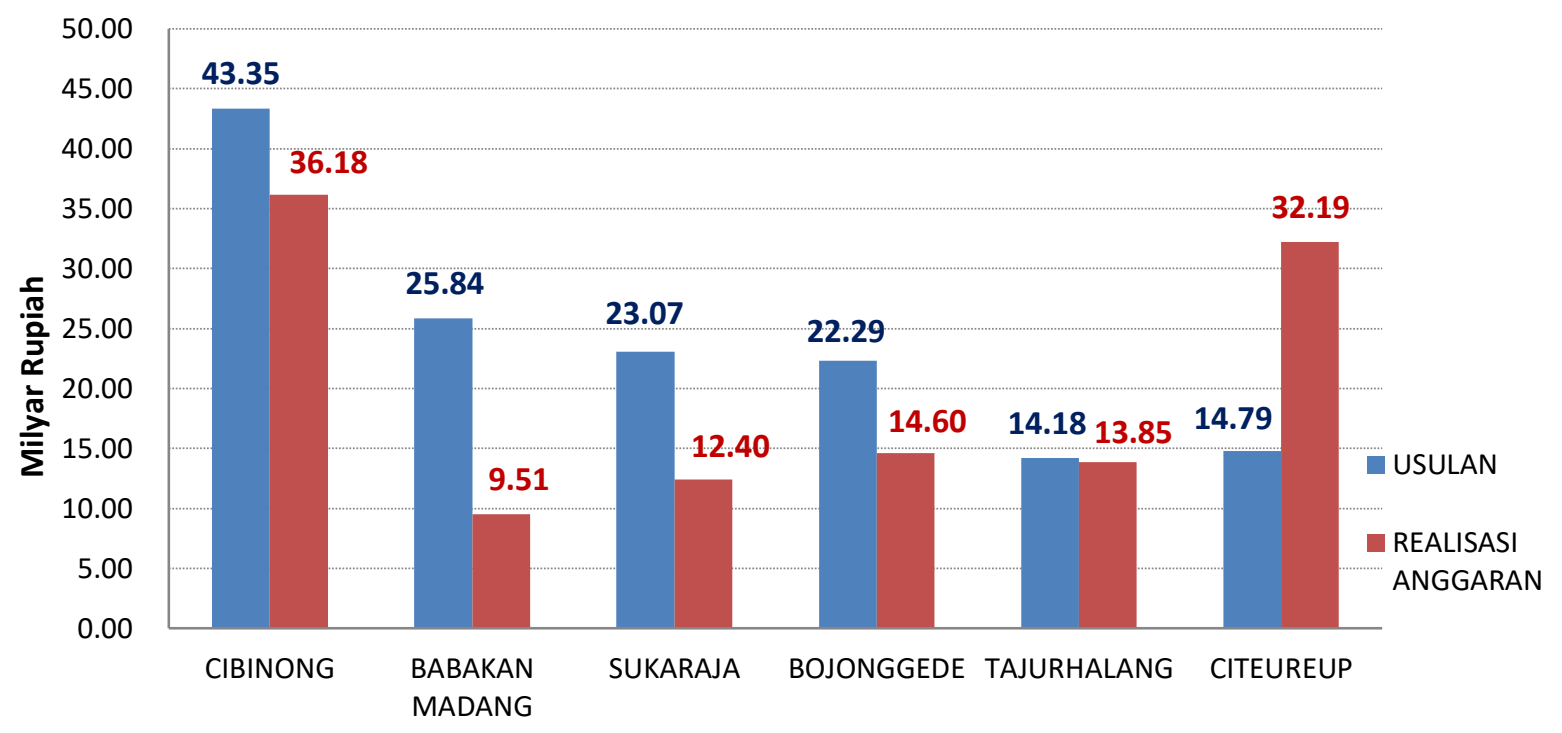

Gambar 1.Perbandingan Usulan Kegiatan dengan Realisasi Anggaran Penanganan Jalan Di Wilayah Cibinong Raya Tahun 2012

Kondisi keterbatasan anggaran pembiayaan pembangunan, pada akhirnya menjadikan skala prioritas menjadi syarat awal penyusunan suatu kegiatan. Berkaitan hal tersebut, maka diperlukan skala prioritas untuk menentukan kegiatan mana yang akan dilaksanakan dan mana yang tidak dalam sebuah anggaran pembangunan. Demikian pula halnya dalam mempertimbangkan skala prioritas pembangunan jalan, maka skala prioritas sebuah proyek pembangunan bisa dinilai dari urgensitasnya, segi kemanfaatan, aspek pelayanan, cakupan masyarakat yang mendapatkan manfaat dari proyek pembangunan itu, dan kemampuan sumber daya.

Terbatasnya anggaran pembiayaan penyelenggaraan infrastruktur jalan di Kabupaten Bogor, pada akhirnya menjadikan skala prioritas sebagai syarat awal penyusunan suatu kegiatan. Namun pada pelaksanaannya masih bersifat common sense atau berdasarkan laporanlaporan hasil observasi para pengamat atau petugas survai yang cenderung subjektif, belum mencerminkan kondisi yang objektif sehingga seringkali warga/ masyarakat atau bahkan pemerintah di tingkat wilayah seperti kecamatan dan kelurahan/desa menilai bahwa skala prioritas penanganan jalan yang ditentukan belum sesuai dengan apa yang mereka butuhkan.

$$
\text { Menurut Dokumen RTRW }
$$

Kabupaten Bogor 2005-2025, Kecamatan Cibinong berada pada wilayah yang memiliki fungsi utama sebagai simpul jasa distribusi pemasaran, produksi dan pusat pelayanan utama untuk wilayah Kabupaten Bogor. Sejauh ini Kecamatan Cibinong lebih didominasi oleh aktivitas pelayanan pemerintahan dibandingkan dengan fungsinya sebagai simpul jasa dan distribusi pemasaran. Kawasan ini sekaligus akan dipersiapkan menjadi Kota Metropolis menyongsong Kota Jakarta yang kelak menjadi Kota Megapolitan.

Kelahiran Kecamatan Cibinong sendiri sebagai ibukota Kabupaten Bogor ditetapkan dengan Peraturan Pemerintah (PP) No.16 tahun 1982, dan pada tanggal 5 Oktober 1985 dilaksanakan peletakkan batu pertama pembangunan Kecamatan Cibinong sebagai ibukota Kabupaten Bogor oleh Bupati Kol. Ci Sudradjat Nataatmadja. Selanjutnya pada awal tahun 1990 Pusat Pemerintahan Kabupaten 
Bogor berlokasi di Kecamatan Cibinong hingga sekarang.

\section{Tujuan}

Berdasarkan latar belakang dan perumusan masalah, tujuan utama dari kajian ini adalah merumuskan suatu model penentuan skala prioritas penyelenggaraan jalan di Kabupaten Bogor. Untuk menjawab tujuan utama tersebut maka tujuan spesifik dari kajian ini adalah :

1. Menganalisis kondisi pelayanan dan kepentingan pemanfaatan jalan Kabupaten yang berada di Kecamatan Cibinong saat ini.

2. Menganalisis penilaian aspek fungsi layanan, aspirasi masyarakat, aspirasi politis, pendekatan teknis sehingga dapat diketahui aspek mana yang paling berpengaruh terhadap penentuan kegiatan penanganan jalan sesuai dengan kebutuhan di Kabupaten Bogor.

3. Menentukan skala prioritas penyelenggaraan jalan di Kecamatan Cibinong Kabupaten Bogor agar lebih objektif dan tepat sasaran.

4. Menentukan strategi alternatif dan program yang dapat dilaksanakan oleh Pemerintah Kabupaten Bogor dalam menyelenggarakan kegiatan penanganan jalan di Kecamatan Cibinong.

\section{TINJAUAN PUSTAKA}

Menurut Undang-Undang RI No.22 Tahun 2009 yang dimaksud dengan jalan adalah seluruh bagian jalan, termasuk bangunan pelengkapnya yang diperuntukan bagi lalu lintas umum, yang berada dibawah permukaan tanah, diatas pemukaaan tanah, dibawah permukaan air, serta diatas pemukaan air, kecuali jalan rel dan jalan kabel. Jalan mempunyai peranan untuk mendorong pembangunan semua satuan wilayah pengembangan, dalam usaha mencapai tingkat perkembangan antar daerah. Jalan merupakan satu kesatuan sistem jaringan jalan yang mengikat dan menghubungkan pusat-pusat pertumbuhan dengan wilayah lainnya.

Terdapat beberapa klasifikasi jalan berdasarkan atas kriterianya berdasarkan UU RI No.22 Tahun 2009, jalan dapat diklasifikasikan berdasarkan (1) atas fungsinya, yaitu jalan arteri, jalan kolektor, dan jalan lokal; (2) muatan sumbu, dibagi dalam beberapa kelas yaitu jalan kelas I, jalan kelas II, jalan kelas III dan jalan kelas khusus; (3) administrasi pemerintahan, dikelopokkan menjadi jalan nasional, jalan provinsi, jalan kabupaten, jalan kota, jalan desa dan jalan khusus.

\section{METODE KAJIAN}

\section{Kerangka Pemikiran}

Berikut pada Gambar 1 dapat dilihat kerangka pemikiran kajian ini, dimana adanya kondisi keterbatasan anggaran pembiayaan pembangunan, pada akhirnya menjadikan skala prioritas menjadi syarat awal penyusunan suatu kegiatan penyelenggaraan jalan di Kecamatan Cibinong, Kabupaten Bogor. Pada kajian ini akan dilihat gambaran Pemerintah Kabupaten Bogor dalam, penyelenggaraan jalan, apakah penyelenggaraan jalan selama ini telah mendukung kawasankawasan strategis yang ada di Kecamatan Cibinong, selanjutnya sejauhmana penyelenggaraan terhadap jalan ini dapat memenuhi beberapa fungsi dari keberadaan jalan berdasarkan UU RI No.22 Tahun 2009. Oleh karena itu perlunya dianalisis suatu skala prioritas dalam penyelenggaraan infrastruktur jalan agar lebih objektif dan tepat sasaran. 


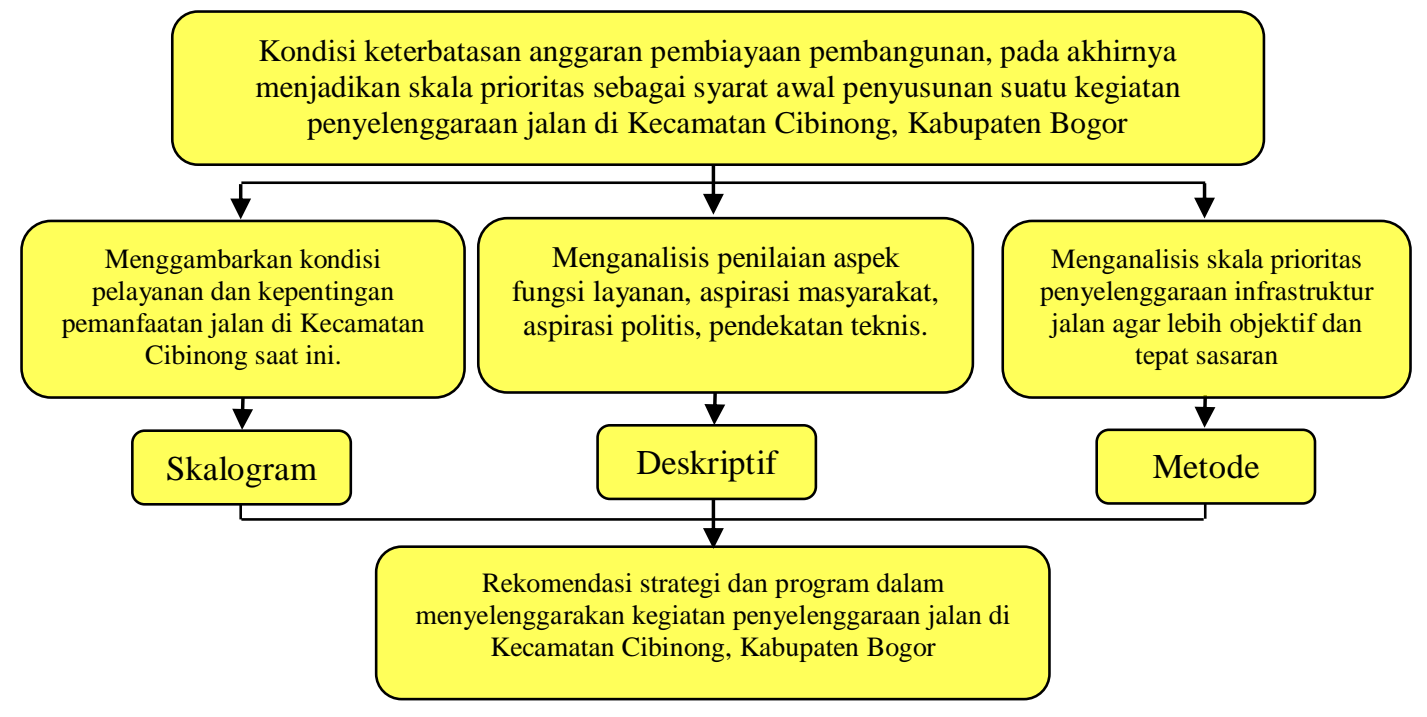

Gambar 2. Kerangka Pemikiran

\section{Lokasi dan Waktu Kajian}

Kajian ini dilakukan di Kecamatan Cibinong, Kabupaten Bogor, dan dilaksanakan selama 6 (enam) bulan dari bulan Mei 2014 sampai dengan Oktober 2014. Dengan batasan waktu data dari tahun 2009 sampai dengan 2013. Pertimbangan pemilihan lokasi kajian antara lain adalah Kecamatan Cibinong merupakan ibu kota Pemerintahan Kabupaten Bogor dan sebagai salah satu hinterland Kota Jakarta serta merupakan kawasan yang dipandang strategis bagi investasi. Kegiatan investasi yang berkembang saat ini perumahan, industri, peternakan, pertambangan dengan sektor perumahan yang paling banyak diminati oleh investor.

\section{Metode Pengumpulan Data}

Rancangan jenis dan sumber data untuk membahas tujuan kajian dapat dilihat pada tabel 1. Data sekunder meliputi data penanganan jalan dari Dinas Bina Marga dan Pengairan tahun 20092013, Badan Perencanaan Pembangunan Daerah, serta dokumen-dokumen terkait penanganan jalan dari instansi/lembaga lain yang terlibat dalam penyelenggaraan jalan di Kabupaten Bogor.

\section{Tabel 1. Keterkaitan antara Tujuan, Data dan Metode Analisis}

\begin{tabular}{|c|c|c|c|c|}
\hline \multirow{2}{*}{ No } & \multirow{2}{*}{ Tujuan } & \multicolumn{2}{|r|}{ Data } & \multirow{2}{*}{ Metode Analisis } \\
\hline & & Jenis & Sumber & \\
\hline 1 & $\begin{array}{l}\text { Menganalisis kondisi pelayanan dan } \\
\text { kepentingan pemanfaatan jalan Kabupaten } \\
\text { yang berada di Kecamatan Cibinong saat ini. }\end{array}$ & $\begin{array}{c}\text { Data } \\
\text { Sekunder }\end{array}$ & $\begin{array}{l}\text { Bappeda \& DBMP } \\
\text { Kab Bogor }\end{array}$ & Analisis Skalogram \\
\hline 2 & $\begin{array}{l}\text { Menganalisis penilaian aspek fungsi } \\
\text { layanan, aspirasi masyarakat, aspirasi politis, } \\
\text { pendekatan teknis, sehingga dapat diketahui } \\
\text { aspek mana yang paling berpengaruh } \\
\text { terhadap penentuan kegiatan penanganan } \\
\text { jalan sesuai. }\end{array}$ & $\begin{array}{c}\text { Data } \\
\text { Sekunder }\end{array}$ & $\begin{array}{c}\text { Bappeda \& DBMP } \\
\text { Kab Bogor }\end{array}$ & Analisis Deskriptif \\
\hline 3 & $\begin{array}{l}\text { Menentukan skala prioritas penyelenggaraan } \\
\text { infrastruktur jalan agar lebih objektif dan } \\
\text { tepat sasaran }\end{array}$ & $\begin{array}{c}\text { Data } \\
\text { Primer }\end{array}$ & $\begin{array}{l}\text { Wawancara } \\
\text { beberapa ahli }\end{array}$ & $\begin{array}{c}\text { Analitical Hierarchy } \\
\text { Process }(A H P)\end{array}$ \\
\hline
\end{tabular}




\section{Variabel Penelitian}

Variabel yang dipakai pada
penelitian ini kriteria/pertimbangan yang menjadi latar belakang prioritas penanganan jalan kabupaten di Kabupaten Bogor, variabel pada penelitian ini baru akan dirumuskan dalam bentuk struktur hirarki setelah didapatkan data sekunder.

Dalam penelitian ini penyusunan level hiraki yang digunakan dalam metode Analytical Hierarchy Process (AHP) terdiri dari 4 (empat) level yaitu :

1. Level I (tujuan), adalah menentukan prioritas jalan yang mendapat prioritas penanganan penyelenggaraan jalan yaitu pembangunan, peningkatan, rehabilitasi serta pemeliharaan secara rutin dan berkala.

2. Level II (Aktor) terdapat di 5 (lima) Aktor yang memiliki peran dalam menentukan penanganan jalan.

3. Level III (Kriteria) terdiri dari beberapa kriteria dalam menentukan prioritas jalan. Kriteria tersebut adalah : Kriteria Fungsi Layanan (A), Kriteria Aspirasi Masyarakat (B), Kriteria Aspirasi Politis (C), Kriteria Pendekatan Teknis (D).

4. Level IV (Pengembangan dari Level III, yang selanjutnya disebut sub kriteria), Sub kriteria melayani : terminal/sub terminal, trayek angkutan umum, pasar, objek wisata, potensi produksi, sarana pendidikan, sarana kesehatan, kantor pemerintahan, selanjutnya diusulkan dalam musyawarah perencanaan pembangunan (musrenbang), rapat mingguan jumat keliling, rabu keliling, kunjungan kerja DPRD, reses DPRD, riwayat penanganan, lebar perkerasan, lebar ruang milik jalan (rumija), keberadaan drainase dan kondisi jalan.

Selanjutnya Penyusunan level hirarki yang terdiri dari 4 (empat) level tersebut diperlihatkan pada Gambar 3, Penyusunan Level Hirarki Penanganan Penyelenggaraan Jalan.

\section{KONDISI UMUM WILAYAH}

\section{Kondisi Geografis dan Administratif}

Kabupaten Bogor secara administratif merupakan bagian dari salah satu kabupaten dalam lingkungan Provinsi Jawa Barat. Luas wilayah Kabupaten Bogor mencapai 298.838,304 hektar yang secara geografis berada diantara $6^{\circ} 19^{\prime}-6^{\circ}$ 47' Lintang Selatan dan $106^{\circ} 1^{\prime}$ - $107^{\circ} 103^{\prime}$ Bujur Timur. Kabupaten Bogor batas-batas wilayah yang berbatasan dengan Kabupaten Tangerang, Kabupaten/Kota Bekasi dan Kota Depok di sebelah Utara, kemuadian dengan Kabupaten Cianjur dan Kabupaten Karawang di sebelah Timur, sementara di sebalah Selatan berbatasan dengan Kabupaten Sukabumi dan Cianjur, sedangkan di sebelah Barat berbatasan dengan Kabupaten Lebak Provinsi Banten serta di tengah-tengah terletak Kota Bogor. Secara administratif, Kabupaten Bogor terdiri atas 434 Desa/Kelurahan yang terdiri dari 417 desa, 17 kelurahan, 3.882 RW, 15.561 RT yang berada dalam 40 Kecamatan.

Kecamatan Cibinong terletak di bagian wilayah tengah yang berfungsi sebagai pusat pelayanan, harus memberikan pelayanan yang seefektif mungkin dengan meningkatkan sarana dan prasarana transportasi yang menghubungkan dengan daerah-daerah di sekitarnya terutama wilayah Barat dan Timur Kabupaten Bogor, serta merangsang atau mendorong perkembangan kawasankawasan produksi yang dilalui oleh jaringan jalan tersebut. 


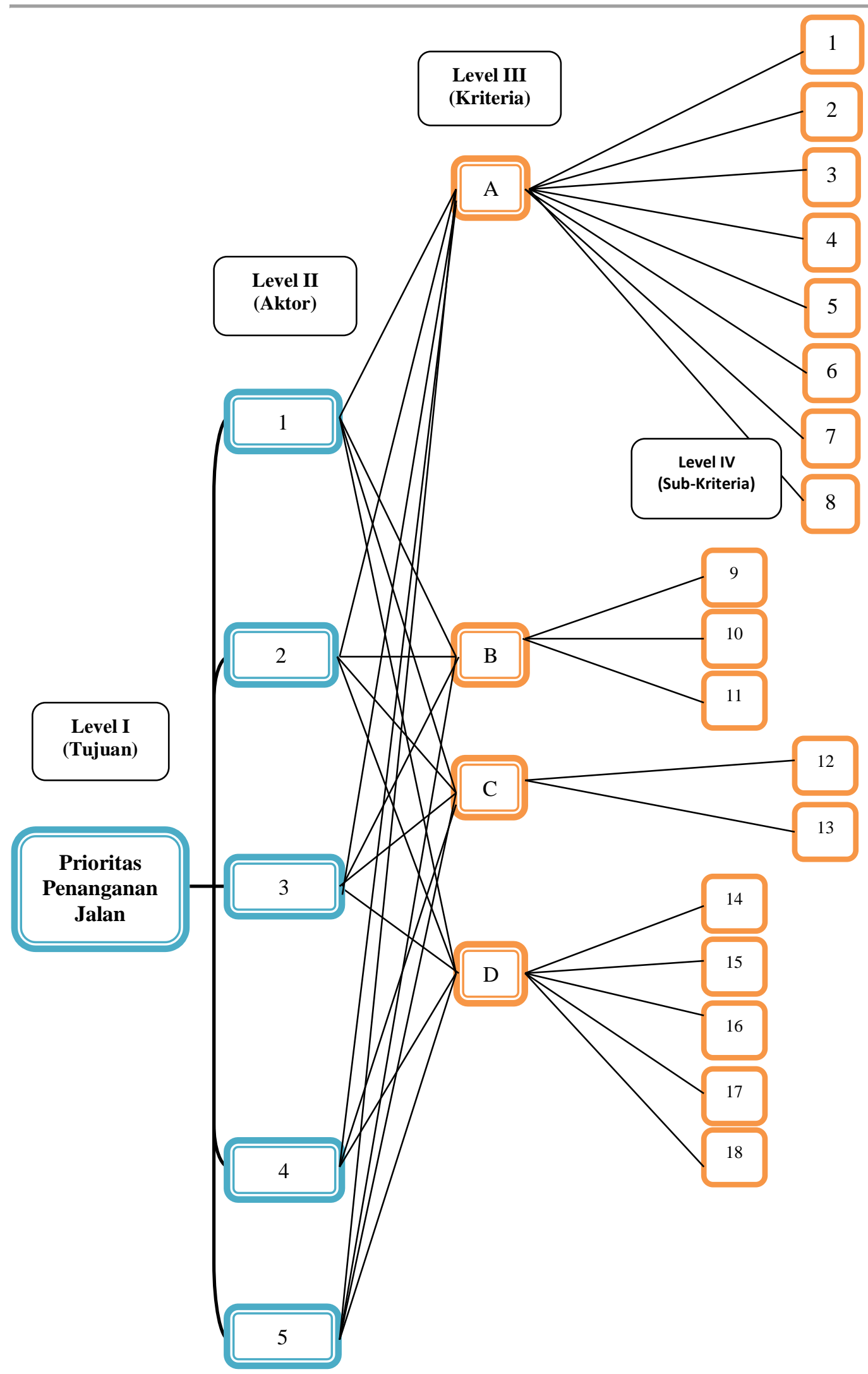




\section{Menurut Dokumen RTRW}

Kabupaten Bogor 2005-2025, Kecamatan Cibinong berada pada wilayah yang memiliki fungsi utama sebagai simpul jasa distribusi pemasaran, produksi dan pusat pelayanan utama untuk wilayah Kabupaten Bogor. Sejauh ini Kecamatan Cibinong lebih didominasi oleh aktivitas pelayanan pemerintahan dibandingkan dengan fungsinya sebagai simpul jasa dan distribusi pemasaran. Kawasan ini sekaligus akan dipersiapkan menjadi Kota Metropolis menyongsong Kota Jakarta yang kelak menjadi Kota Megapolitan. Kelahiran Kecamatan Cibinong sendiri sebagai ibukota Kabupaten Bogor ditetapkan dengan Peraturan Pemerintah (PP) No.16 tahun 1982, dan pada tanggal 5 Oktober 1985 dilaksanakan peletakkan batu pertama pembangunan Kecamatan Cibinong sebagai ibukota Kabupaten Bogor oleh Bupati Kol. Ci Sudradjat Nataatmadja. Selanjutnya pada awal tahun 1990 Pusat Pemerintahan Kabupaten Bogor berlokasi di Kecamatan Cibinong hingga sekarang.

Prasarana jalan merupakan salah satu unsur yang cukup strategis dalam menunjang pembangunan disamping dapat mempercepat arus kegiatan, ekonomi serta memperlancar mobilitas penduduk antar daerah. Dengan semakin meningkatnya aktifitas pembangunan maka dituntut pula adanya jaringan jalan yang semakin memadai. Di Kabupaten Bogor terdapat jalan dengan panjang total $1.996,485 \mathrm{Km}$ (480 ruas jalan), yaitu terdiri dari $1.748,915 \mathrm{Km}$ Jalan Kabupaten (458 ruas jalan) kemudian 126,380 Jalan Provinsi (10 ruas jalan) dan 121,190 Km Jalan Nasional (12 ruas jalan). Jumlah ruas jalan tersebut berada dalam pengawasan 10 wilayah Unit Pelaksana Teknis (UPT) Jalan dan Jembatan yang tersebar di 40 Kecamatan.

\section{PRIORITAS PENYELENGGARAAN} JALAN

\section{Fungsi Layanan Terhadap Ruas Jalan di Kecamatan Cibinong}

Dalam menentukan skala priortas penanganan jalan di Kecamatan Cibinong Kabupaten Bogor terdapat penilaian terhadap 8 (delapan) sub kriteria dari kriteria Fungsi Layanan yang terdiri dari melayani terminal/sub terminal, melayani trayek angkutan umum, melayani pasar, melayani objek wisata, melayani potensi produksi, melayani sarana pendidikan, melayani sarana kesehatan dan melayani kantor pemerintahan. Penilaian selanjutnya dilakukan terhadap 5 (lima) sub kriteria dari kriteria Aspirasi dan 5 (lima) sub kriteria dari kriteria Teknis.

Berdasarkan fungsi melayani sub terminal/sub terminal, Kecamatan Cibinong memiliki 6 (enam) ruas jalan yang melayani terminal/sub terminal. Ruas jalan tersebut yaitu : Sukahati-Kedung Halang, Sukahati-Bojong Gede, Kampung Pos-Harapan Jaya, Ciriung-Curug, Ciriung-Cibinong, dan jalan Lingkar Pasar Cibinong. Ke-enam jalan tersebut berada di Kelurahan Sukahati, Karadenan, Pakansari, Pabuaran, Harapan Jaya, Ciriung, Cirimekar, dan Cibinong.

Selanjutnya untuk fungsinya dalam melayani trayek angkutan umum, Kecamatan Cibinong memiliki 6 (enam) ruas jalan yang dilalui oleh trayek angkutan umum yaitu : Sukahati-Kedung Halang, Sukahati-Bojong Gede, Kampung Pos-Harapan Jaya, Ciriung-Curug, Ciriung-Cibinong, dan jalan Lingkar Pasar Cibinong. Ke-enam jalan tersebut berada di Kelurahan Sukahati, Karadenan, Pakansari, Pabuaran, Harapan Jaya, Ciriung, Cirimekar, dan Cibinong.

Terdapat 8 (delapan) ruas jalan di Kecamatan Cibinong yang melayani pasar yaitu : Sukahati-Kedung Halang, SukahatiBojong Gede, Kampung Pos-Harapan Jaya, Harapan Jaya-Alfalah, CibinongAlfalah, Ciriung-Curug, Ciriung-Cibinong dan jalan Lingkar Pasar Cibinong. Ruas- 
ruas jalan yang melayani pasar di Kecamatan Cibinong berada di Kelurahan Sukahati, Karadenan, Pakansari, Pabuaran, Harapan Jaya, Nanggewer, Ciriung, Cirimekar dan Cibinong.

Infrastruktur jalan di Kecamatan Cibinong pun memiliki fungsi Melayani Objek Wisata. Terdapat satu objek wisata yang ada di Kecamatan Cibinong, yaitu Setu Cikaret, tempat wisata ini didukung oleh jalan Lingkar Setu Cikaret yang berada di Kelurahan Harapan Jaya.

Fungsi selanjutnya Melayani Potensi Produksi, dibagi kedalam 2 (dua) kategori yaitu sub sektor pertanian tanaman pangan dan perkebunan serta katergori sub sektor peternakan. Kategori pertanian tanaman pangan dan perkebunan yang tumbuh di Kecamatan Cibinong meliputi padi, jagung, ubi kayu, jambu biji, jambu air, mangga, pepaya, pisang dan rambutan.

Daerah penghasil ubi kayu di Kecamatan Cibinong berasal dari Kelurahan Keradenan dengan produksi tertinggi yaitu sebesar 430 ton, penghasil padi tertinggi di Kecamatan Cibinong dengan produksi di tahun 2012 sebesar 146 ton, manakala untuk sub sektor perkebunan, Kelurahan Pondok Rajeg dan Harapan Jaya merupakan daerah penghasil jambu air terbesar di Kecamatan Cibinong dengan produksi sebesar 7,2 ton, Sedangkan untuk buah rambutan, Kelurahan Cibinong, Pondok Rajeg dan Keradenan merupakan tiga kelurahan penghasil rambutan terbesar di Kecamatan Cibinong.

Hasil dari produksi ini didukung oleh 8 (delapan) ruas jalan yaitu SukahatiKedung Halang, Sukahati-Bojonggede, Cirimekar-Bek Ang, jalan Masuk Perum Pemda, jalan Masuk SDN Kaum Pandak, jalan Masuk SMK Terpadu Cibinong, Ciriung-Cibinong dan jalan Dr. Nurdin.

Sarana pendidikan yang ada di Kecamatan Cibinong mencakup mulai dari tingkat Taman Kanak-kanak (TK), Sekolah Dasar (SD), SLTP, sampai dengan SLTA. Sekolah TK berada di Kelurahan
Karadenan, SD paling banyak di Kelurahan Pabuaran, SLTP berada 2 (dua) unit di Kelurahan Karadenan, 1 (satu) unit di Kelurahan Sukahati dan 1 (unit) di Kelurahan Ciriung, dan SLTA berada 2 (unit) di Kelurahn Karadenan, 1 (satu) unit di Kelurahan Nanggewer serta 1 (satu) unit di Kelurahan Ciriung. Seluruh sarana pendidikan yang berada di Kecamatan Cibinong didukung oleh 27 ruas jalan.

Selanjutnya, untuk sarana kesehatan, beberapa sarana kesehatan yang terdapat di Kecamatan Cibinong meliputi Rumah Sakit (RS) dengan jumlah 6 (enam) unit, Puskesmas Pembantu (Pustu) dengan jumlah 6 (enam) unit, Pos Pelayanan Terpadu (Posyandu) dengan jumlah 198 unit, Pos Keluarga Berencana (KB) tersedia 12 unit di tiap kelurahan dan Balai Pengobatan berjumlah 40 unit. Seluruh sarana kesehatan yang berada di Kecamatan Cibinong didukung oleh 27 ruas jalan.

Mengingat fungsinya sebagai ibu kota pemerintahan Kabupaten Bogor, maka lebih dari setengah jumlah ruas jalan yang ada di Kecamatan Cibinong melayani Kantor Pemerintahan. Salah satunya ruas Jalan Lingkar Kantor Pemda Cibinong yang melayani lebih dari 20 kantor pemerintah karena lokasi Organisasi Perangkat Daerah (OPD) terpusat di Kelurahan Tengah. Terdapat 11 ruas jalan yang tidak secara langsung melayani kantor-kantor pemerintahan yaitu : Jalan Curug-Ciriung, Jalan Masuk Perum Pemda, Jalan Masuk Perum DPRD, Jalan Masuk Perum DPRD, Jalan Masuk RS Cibinong, Jalan Kandang Roda-Pakan Sari, Jalan H Nawawi, Jalan Masuk SDN Kaum Pandak, Jalan Masuk SMK Terpadu Cibinong, Jalan Pakansari Sirojul Munir, Jalan SMU Cibinong dan Jalan Lingkar Pasar Cibinong.

\section{Prioritas Penyelenggaraan jalan Di Kecamatan Cibinong}

Berdasarkan hasil analiisis $A H P$ menggunakan expertchoice, aktor yang sangat menentukan penanganan jalan di 
Kecamatan Cibinong adalah Bappeda dengan nilai skor adalah 0,425. Hal ini karena Bappeda merupakan lembaga yang berperan dalam menentukan program dan kegiatan di pemerintah daerah. Selanjutnya adalah Dinas Bina Marga dan Pengairan dengan nilai sebesar 0,235. Dinas ini merupakan pelaksana teknis dari hal yang sudah disiapkan oleh Bappeda berdasarkan kegiatan dan program yang ada di RKPD. Aktor selanjutnya yang menentukan penanganan jalan adalah Pemerintah Kecamatan, DPRD dan kalangan pengusaha/swasta dengan nilai masing-masing adalah 0,166, 0,108 dan 0,067 .

Selanjutnya, kriteria yang sangat menentukan penanganan jalan adalah kriteria fungsi layanan dengan nilai sebesar 0,467 . Ini menandakan bahwa fungsi layanan dari jalan sangat menentukan penanganan jalan. Selanjutnya adalah berdasarkan atas kriteria teknis, aspirasi masyarakat dan aspirasi politis dengan masing-masing nilai adalah $0,277,0,160$ dan 0,095.

Analisis sub kriteria dibagi menjadi dua, yaitu berdasarkan atas kriteria serta dibandingkan secara keseluruhan. Sub kriteria yang paling diprioritaskan secara rata-rata adalah melayani sub terminal dengan nilai 0,193 , selanjutnya adalah melayani trayek angkot dengan nilai 0,160. Dari kedua prioritas tertinggi dari sub kriteria fungsi layanan ini, ternyata mengarah kepada pelayanan terhadap masyarakat melalui transportasi umum. Sub kriteria selanjutnya adalah melayani kantor pemerintah dan pasar dengan nilai masing-masing adalah 0,152 dan 0,120. Sementara itu pelayanan jalan untuk sarana pertanian, seperti melayani sarana potensi produksi menempati prioritas keenam, ini perlu ditingkatkan lagi, mengingat Kabupaten Bogor berusaha untuk merevitalisasi sektor pertaniannya. Jika pelayanan untuk potensi produksi ini lebih diprioritaskan maka program revitalisasi pertanian Pemerintah Kabupaten Bogor akan lebih berhasil. Begitu juga untuk pelayanan pendidikan dan kesehatan yang menempati urutan ke lima dan tujuh, sehingga dapat dikatahan bahwa penanganan pelayanan jalan belum terlalu memprioritaskan sektor keshatan dan pendidikan.

Selanjutnya, sub kriteria aspirasi masyarakat, yang paling diprioritskan berasal dari Musrembang, dengan nilai 0,540, dimana pada musrembang ini dilakukan secara bertahap, dari tingkat desa, kecamatan hingga kabupaten, bahkan hingga tingkat provinsi dan nasional.

Sementara reses anggota DPRD merupakan sub kriteria yang sangat diprioritaskan dalam penentuan penanganan jalan di Kecamatan Cibinong, Kabupaten Bogor melalui asirsi politis dengan nilai 0.533 . Selanjutnya untuk sub kriteria teknis, ruang milik jalan dan kondisi jalan merupakan sub kriteria yang sangat mnentukan dalam penanganan jalan. Kedua hal ini sangat penting dalam sub kriteria teknis, karena dari keduanya dapat ditentukan kesesuaian status dari suatu jalan, apakah suatu jalan sudah layak disebut jalan kabupaten atau masih tingkat kecamatan dan desa.

Berdasarkan hasil AHP terhadap seluruh sub kriteria, sub kriteria melayani trayek angkutan dan melayani terminal/sub terminal sangat diprioritaskan, dengan nilai masing-masing adalah 0,112 dan 0,110 . Hal ini dikarenakan Kabupaten Bogor merupakan salah satu daerah penyangga ibukota Jakarta, sehingga tidak sedikit masyarakatnya yang bekerja di ibukota. Unutk mempermudah kegiatan warganya, maka dipermudahlah transportasi masyarakat di Kabupaten Bogor, khususnya di Kecamatan Cibinong.

Sub kriteria selanjutnya adalah berdasarkan hasil musrembang dengan nilai 0,087 . Sedangkan dua sub kriteria teksnis yang tertinggi adalah riwayat penanganan dan ruang milik jalan. Hal ini disebabkan tidak sedikit jalan di Kabuptean Bogor, khususnya di Kecamatan Cibinong yang terlalu dipaksakan statusnya, seperti beberapa 
jalan sebetulnya dalam status jalan desa/kecamatan, tetapi dipaksakan menjadi jalan kabupten. Ini berdampak tidak baik, karena tidak sesuai secara kriteria teksnis, seperti kurang lebarnya jalan tersebut.

Keterkaitan antara ruas jalan dan fungsi dari sub kriteria penanganan jalan yang diprioritaskan yang telah diberi bobot AHP, berdasarkan hasil analisis, terdapat 6 (enam) ruas jalan yang paling diprioritaskan dalam penanganannya, yaitu ruas jalan Ciriung-Cibinong, SukahatiKedung Halang, Kampung Pos-Harapan Jaya, Sukahati-Bojojng Gede, CiriungCurug dan jalan Lingkar Pasar Cibinong. Ke-enam ruas jalan ini memiliki hampir semua sub kriteria yang ada, kecuali sub kriteria Jumat Keliling, Rabu Keliling, Kunjungan Kerja DPRD dan Reses DPRD. Artinya tanpa harus diusulkan dalam kegiatan yang bersifat mengumpulkan aspirasi dari masyarakat, ruas-ruas jalan ini sudah menjadi ruas jalan yang dianggap penting karena telah memenuhi kriteria fungsi layanan dan kriteria teknis.

melayani terminal/sub-terminal,

Berdasarkan atas fungsinya dalam Kecamatan Cibinong memiliki 6 (enam) ruas jalan yang melayani terminal/sub terminal. Ruas jalan tersebut yaitu : Sukahati-Kedung Halang, SukahatiBojong Gede, Kampung Pos-Harapan Jaya, Ciriung-Curug, Ciriung-Cibinong, dan jalan Lingkar Pasar Cibinong. Keenam jalan tersebut berada di Kelurahan Sukahati, Karadenan, Pakansari, Pabuaran, Harapan Jaya, Ciriung, Cirimekar, dan Cibinong.

Selanjutnya untuk fungsi ruas jalan dalam melayani trayek angkutan umum di Kecamatan Cibinong, terdapat 6 (enam) ruas jalan yang dilalui oleh trayek angkutan umum yaitu : Sukahati-Kedung Halang, Sukahati-Bojong Gede, Kampung Pos-Harapan Jaya, Ciriung-Curug, Ciriung-Cibinong, dan jalan Lingkar Pasar Cibinong. Ke-enam jalan tersebut berada

44 di Kelurahan Sukahati, Karadenan, Pakansari, Pabuaran, Harapan Jaya, Ciriung, Cirimekar, dan Cibinong.
Terdapat 8 (delapan) ruas jalan di Kecamatan Cibinong yang melayani pasar yaitu : Sukahati-Kedung Halang, SukahatiBojong Gede, Kampung Pos-Harapan Jaya, Harapan Jaya-Alfalah, CibinongAlfalah, Ciriung-Curug, Ciriung-Cibinong dan jalan Lingkar Pasar Cibinong. Ruasruas jalan yang melayani pasar di Kecamatan Cibinong berada di Kelurahan Sukahati, Karadenan, Pakansari, Pabuaran, Harapan Jaya, Nanggewer, Ciriung, Cirimekar dan Cibinong.

Di Kecamatan Cibinong hanya ada satu objek wisata yaitu Setu Cikaret yang berlokasi di Kelurahan Harapan Jaya. Objek wisata tersebut dilayani oleh jalan Lingkar Setu Cikaret sepanjang $800 \mathrm{~m}$.

Untuk hasil produksi pertanian tanaman pangan hampir seluruh ruas jalan mendukung atau melayani fungsi layanan tersebut. Hanya terdapat 3 (tiga) ruas jalan kurang mendukung potensi produksi pertanian tanaman pangan yaitu : ruas jalan Cibinong-Pekapuran, Cibinong-Alfalah dan Pabuaran-Cikaret.

Sedangkan untuk hasil produksi pertanian perkebunan dilayani seluruhhnya oleh ruas-ruas jalan yang terdapat di Kecamatan Cibinong. Begitu juga untuk sarana pendidikan dan kesehatan didukung oleh 27 ruas jalan yang ada di Kecamatan Cibinong.

Sementara untuk pelayanan terhadap kantor pemerintah di lingkungan Kecamatan Cibinong, terdapat Terdapat 11 ruas jalan yang tidak secara langsung melayani kantor-kantor pemerintahan yaitu : Jalan Curug-Ciriung, Jalan Masuk Perum Pemda, Jalan Masuk Perum DPRD, Jalan Masuk Perum DPRD, Jalan Masuk RS Cibinong, Jalan Kandang Roda-Pakan Sari, Jalan H Nawawi, Jalan Masuk SDN Kaum Pandak, Jalan Masuk SMK Terpadu Cibinong, Jalan Pakansari Sirojul Munir, Jalan SMU Cibinong dan Jalan Lingkar Pasar Cibinong.

Jika dilihat dari kriteria aspirasi masyarakat dan aspirasi politis, keseluruhan ruas jalan yang berstatus Jalan Kabupaten hanya diusulkan dalam forum 
Musyawarah Perencanaan Pembangunan (Musrenbang).

Berdasarkan hasil penlaian terhadap Kriteria Teknis didapat ruas jalan yang mendapatkan nilai terbesar $(2,85)$ adalah ruas Jalan SMU Cibinong, sedangkan ruas jalan yang mendapatkan nilai paling rendah $(0,46)$ adalah Jalan Pabuaran-Cikaret.

\section{RANCANGAN STRATEGI DAN PROGRAM}

$\begin{array}{cccr} & \text { Berdasarkan hasil analisis, } & \text { ham } \\ \text { terdapat } & 4 \quad \text { (empat) } & \text { strategi } & \text { dalam }\end{array}$
menyelenggarakan kegiatan penanganan jalan, yaitu: (1) Mempertahankan kondisi jalan pada ruas jalan yang menjadi Prioritas; (2) Strategi meningkatkan kualitas konstruksi pada ruas jalan prioritas; (3) Strategi mengoptimalkan lebar perkerasan pada ruas jalan prioritas dan (4) membenahi ruang milik jalan (Rumija) pada ruas jalan yang belum memenuhi ketentuan.

\section{Mempertahankan Kondisi Jalan Pada Jalan Prioritas}

Dari hasil analisis dapat diurutkan dari 6 (enam) ruas jalan yang memiliki nilai tertinggi yaitu ruas jalan : CiriungCibinong, Sukahati-Kedung Halang, Kampung Pos-Harapan Jaya, SukahatiBojong Gede, Ciriung-Curug dan Jalan Lingkar Pasar Cibinong. Ke-enam jalan tersebut unggul karena memiliki bobot nilai pada Kriteria Fungsi Layanan tepatnya pada Sub Kriteria Melayani Terminal/Sub Terminal, Melayani Trayek Angkutan Umum, Melayani Pasar, Potensi Produksi, Sarana Kesehatan dan Sarana Pendidikan.

$\begin{array}{rrr}\text { Oleh } & \text { karena itu } & \text { strategi yang } \\ \text { dihasilkan } & \text { adalah } & \text { Strategi }\end{array}$
mempertahankan kondisi kualitas jalan pada ruas jalan prioritas. Hal ini perlu dilakukan karena ke-enam jalan tersebut memiliki tingkat pelayanan yang tinggi (high level of service). Strategi ini dapat diaplikasikan pada Program Pemeliharaan
Jalan yang bersifat rutin. Artinya ruas jalan prioritas ini perlu dianggarkan disetiap tahunnya agar kondisinya selalu mantap. Selain itu dapat dilakukan suatu koordinasi dengan Dinas Lalu Lintas Angkutan Jalan Kabupaten Bogor untuk mengatur lalu lintas guna mengawasi kendaraan yang memiliki beban berat agar tidak melewati jalan-jalan tersebut. Program terkait dengan strategi ini dapat diuraikan pada kegiatan Pemeliharaan Ruas Jalan :

1. Ciriung-Cibinong (Sta. 0+000 - Sta. 2+300)

2. Sukahati-Kedung Halang (Sta. $0+000$ - Sta. 7+650)

3. Kampung Pos-Harapan Jaya (Sta. 0+000 - Sta. 2+800)

4. Sukahati-Bojong Gede (Sta. 0+000 Sta. 3+350)

5. Ciriung-Curug (Sta. $0+000-$ Sta. $1+500)$

6. Jalan Lingkar Pasar Cibinong (Sta. 0+000 - Sta. 0+900)

\section{Meningkatkan Kualitas Konstruksi pada ruas Jalan Prioritas}

Enam ruas jalan prioritas yang memiliki nilai Fungsi Layanan tinggi ini tentunya menanggung beban lebih dibandingkan ruas jalan lainnya. Maka selain mempertahankan kondisi dengan memelihara setiap tahun, penanganan lain yang dapat dilakukan oleh Pemerintah Daerah Kabupaten Bogor adalah meningkatkan kualitas konstruksi dari ruas jalan tersebut. Oleh karena itu strategi yang dihasilkan adalah Strategi meningkatkan kualitas konstruksi pada ruas jalan prioritas. Hal ini perlu dilakukan mengingat ke-enam jalan prioritas ini memiliki tingkat pelayanan yang tinggi dalam melayani potensi produksi yang akan menimbulkan bangkitan kendaraan-kendaraan dengan tonase yang besar. Strategi ini dapat diaplikasikan pada Program Peningkatan Jalan dengan bekerja sama dengan Dinas Lalu Lintas Angkutan Jalan Kabupaten Bogor terkait inventarisasi arus lalu lintas pada ruas-ruas jalan tersebut. 
Program terkait dengan strategi ini dapat diuraikan pada kegiatan Peningkatan Ruas Jalan :

1. Ciriung-Cibinong (Sta. 0+000 - Sta. 2+300)

2. Sukahati-Kedung Halang (Sta. 0+000 Sta. 7+650)

3. Kampung Pos-Harapan Jaya (Sta. 0+000 - Sta. 2+800)

4. Sukahati-Bojong Gede (Sta. 0+000 Sta. 3+350)

5. Ciriung-Curug (Sta. $0+000-$ Sta. $1+500)$

6. Jalan Lingkar Pasar Cibinong (Sta. $0+000$ - Sta. 0+900)

\section{Mengoptimalkan Lebar Perkerasan Pada Jalan Prioritas}

Hasil analisis menunjukan bahwa masih terdapat 17 ruas jalan yang memiliki lebar badan jalan kurang optimal. Ruasruas jalan tersebut adalah : CibinongPekapuran, Jalan Masuk Puskesmas Cirimekar, Jalan Sirojul Munir, Harapan Jaya-Alfalah, Cibinong-Alfalah, CiriungCurug, Jalan Lingkar Setu Cikaret, Jalan Masuk Perum Pemda, Jalan Masuk Perum DPRD, Jalan Masuk RS Cibinong, ruas Jalan Kandang roda-Pakansari, Jalan $\mathrm{H}$ Nawawi, Jalan Masuk SDN Kaum Pandak, Jalan Masuk SMK Terpadu Cibinong, ruas Pabuaran-Cikaret, Pakansari-Sirojul Munir dan Jalan SMU Cibinong. Atas dasar hal tersebut strategi yang dihasilkan adalah Strategi mengoptimalkan lebar perkerasan pada jalan prioritas. Strategi ini perlu dilakukan agar selain dapat memperlancar arus lalu lintas, kenyamanan pengguna jalan dalam bermanuver pun dapat tercapai. Program yang dapat dicanangkan Pemerintah Daerah Kabupaten Bogor khususnya Dinas Bina Marga dan Pengairan (DBMP) adalah Program Optimalisasi Bahu Jalan.

Program terkait dengan strategi ini dapat diuraikan pada kegiatan Optimalisasi bahu ruas jalan :

1. Cibinong-Pekapuran

2. Jalan Masuk Puskesmas Cirimekar
3. Jalan Sirojul Munir

4. Harapan Jaya-Alfalah

5. Cibinong-Alfalah

6. Ciriung-Curug

7. Lingkar Setu Cikaret

8. Jalan Masuk Perum Pemda

9. Jalan Masuk Perum DPRD

10. Jalan Masuk RS Cibinong

11. Kandang Roda-Pakansari

12. Jalan H Nawawi

13. Jalan Msk SDN Kaum Pandak

14. Jalan Msk SMK Terpadu Cbng

15. Pabuaran-Cikaret

16. Pakansari-Sirojul Munir

17. Jalan SMU Cibinong

\section{Membenahi Ruang Milik Jalan (Rumija) Agar Sesuai Dengan Ketentuan}

Berdasarkan hasil analisis pada ruas jalan yang ada di Kecamatan Cibinong ditemukan 7 (tujuh) ruas jalan yang tidak sesuai dengan apa yang diamanatkan pada Peratuan Pemerintah Nomor 26 Tahun 1985 tentang Jalan. Ruas jalan tersebut yaitu : Ruas Jalan Cibinong-Pekapuran, Ciriung-Curug, Lingkar Setu Cikaret, Jalan Masuk RS Cibinong, Kandang RodaPakansari, Jalan $\mathrm{H}$ Nawawi dan Jalan Masuk SDN Kaum Pandak. Maka dari itu strategi yang dihasilkan adalah Strategi membenahi ruang milik jalan (Rumija) pada ruas-ruas jalan prioritas agar sesuai dengan apa yang telah diamanatkan dalam Peratuan Pemerintah Nomor 26 Tahun 1985 tentang Jalan. Hal ini perlu dilakukan untuk menghindari permasalahan-permasalahan sosial yang muncul di kemudian hari, ketika ruas-ruas jalan tersebut semakin meningkat baik fungsi layanan maupun statusnya.

Program terkait dengan strategi ini dapat diuraikan pada kegiatan Pembebasan Tanah ruas jalan:

1. Cibinong-Pekapuran

2. Ciriung-Curug

3. Jalan Lingkar Setu Cikaret

4. Jalan Masuk RS Cibinong

5. Kandang Roda-Pakansari 
6. Jalan H Nawawi

7. Jalan Masuk SDN Kaum Pandak

\section{Implikasi Kebijakan}

Berdasarkan atas strategi yang telah dirumuskan, berbagai kegiatan perlu dilakukan agar strategi yang ada dapat berjalan dengan baik. Beberapa hal yang perlu diperhatikan adalah :

1. Perlu dilakukan pemeliharaan rutin pada ruas-ruas jalan prioritas yang memiliki fungsi layanan tinggi (high level of service) untuk menjaga kondisi jalan agar tetap prima.

2. Ruas-ruas jalan yang memiliki tingkat pelayanan sedang dan rendah, dapat dilakukan pemeliharaan yang bersifat berkala. Artinya tidak perlu dilakukan pemeliharaan setiap tahun tetapi bisa dilakukan tiga atau empat tahun sekali.

3. Ruas jalan dengan kondisi rusak berat agar ditangani ditahun pertama. Perbaikan terhadap ruas jalan SMU Cibinong, kandang Roda - Pakansari dan jalan $\mathrm{H}$ Nawawi sangat perlu dilakukan mengingat jalan tersebut berstatus jalan Kabupaten yang sudah menjadi kewajiban dan tanggung jawab Pemerintah Daerah Kabupaten Bogor dalam melayani masyarakatnya.

4. Peningkatan mutu atau kualitas dari konstruksi pada jalan prioritas dapat dilakukan berurutan setiap tahun sesuai urutan prioritas jalan di Kecamatan Cibinong.

5. Untuk mengoptimalkan lebar perkerasan badan jalan dapat dilakukan mengikuti jadual pemeliharaan sesuai dengan kepentingan jalan yang berada di Kecamatan Cibinong.

6. Penyesuaian dimensi ruang milik jalan (rumija) yang belum sesuai dengan ketentuan harus dilakukan berurutan mulai dari pembebasan tanah kemudian di tahun berikutnya dilanjutkan dengan kegiatan pelebaran jalannya, agar tidak timbul masalah baru terkait tanah yang sudah dibebaskan oleh Pemerintah Daerah kabupaten Bogor.

\section{SIMPULAN DAN SARAN}

\section{Simpulan}

1. Berdasarkan atas fungsinya dalam melayani terminal/sub terminal, dan trayek angkutan umum Kecamatan Cibinong memiliki 6 (enam) ruas jalan yang melayani sub kriteria tersebut. Ruas jalan dimaksud yaitu : Sukahati-Kedung Halang, Sukahati-Bojong Gede, Kampung Pos-Harapan Jaya, Ciriung-Curug, Ciriung-Cibinong, dan jalan Lingkar Pasar Cibinong. Ke-enam jalan tersebut berada di Kelurahan Sukahati, Karadenan, Pakansari, Pabuaran, Harapan Jaya, Ciriung, Cirimekar, dan Cibinong. Selanjutnya terdapat 8 (delapan) ruas jalan di Kecamatan Cibinong yang melayani pasar yaitu : Sukahati-Kedung Halang, Sukahati-Bojong Gede, Kampung Pos-Harapan Jaya, Harapan JayaAlfalah, Cibinong-Alfalah, CiriungCurug, Ciriung-Cibinong dan jalan Lingkar Pasar Cibinong. Ruas-ruas jalan yang melayani pasar di Kecamatan Cibinong berada di Kelurahan Sukahati, Karadenan, Pakansari, Pabuaran, Harapan Jaya, Nanggewer, Ciriung, Cirimekar dan Cibinong.

Sementara hanya terdapat satu ruas jalan saja yang melayani objek wisata yaitu ruas jalan Lingkar Setu Cikaret di Kelurahan Harapan Jaya. Sedangkan untuk melayani potensi produksi, sarana pendidikan, kesehatan dan kantor pemerintahan hampir seluruhnya dilayani oleh ruas-ruas jalan yang terdapat di Kecamatan Cibinong.

2. Berdasarkan hasil AHP, didapat kriteria yang sangat menentukan penanganan jalan di Kecamatan Cibinong, Kabupaten Bogor adalah kriteria fungsi layanan, selanjutnya adalah berdasarkan atas kriteria 
teknis, aspirasi masyarakat dan aspirasi politis.

3. Berdasarkan hasil analisis setiap sub kriteria terhadap ruas jalan di Kecamatan Cibinong, terdapat 6 (enam) ruas jalan yang paling diprioritaskan dalam penanganannya, yaitu ruas jalan Ciriung-Cibinong, SukahatiKedung Halang, Kampung PosHarapan Jaya, Sukahati-Bojojng Gede, Ciriung-Curug dan jalan Lingkar Pasar Cibinong.

4. Berdasarkan hasil analisis, terdapat 4 (empat) strategi dalam menyelenggarakan kegiatan penanganan jalan, yaitu: (1) Mempertahankan kondisi jalan pada ruas jalan yang menjadi Prioritas; (2) Strategi meningkatkan kualitas konstruksi pada ruas jalan prioritas; (3) Strategi mengoptimalkan lebar perkerasan pada ruas jalan prioritas dan (4) membenahi ruang milik jalan (Rumija) pada ruas jalan yang belum memenuhi ketentuan.

\section{Saran}

1. Sehubungan kajian ini hanya dilakukan di satu kecamatan yang merupakan ibu kota kabupaten, yaitu Kecamatan Cibinong, maka akan lebih baik jika dilakukan kajian dengan skala yang lebih luas untuk seluruh Kabupaten Bogor agar dapat diketahui karakter dari masing-masing wilayah/kecamatan.

2. Kajian dapat dilakukan tidak hanya terhadap ruas jalan yang berstatus Jalan Kabupaten tetapi juga terhadap ruas-ruas jalan desa/kelurahan.

3. Kajian selanjutnya dapat membahas mengenai hubungan antara anggaran yang dikeluarkan oleh Pemerintah Kabupaten Bogor dalam penanganan jalan dengan dampaknya terhadap perekonomian masyarakat.
4. Perlu dipertimbangkan keterkaitan antara penanganan jalan dengan jumlah ketersediaan sumberdaya manusia yang ada di Pemerintah Daerah Kabupaten Bogor, agar penanganan jalan lebih optimal dan tepat sasaran.

\section{DAFTAR PUSTAKA}

Afriansyah R. 2012. Penentuan Prioritas Pengembangan Jaringan Jalan Pendukung Kawasan Strategis Di Pulau Summbawa. Jurnal Rekayasa Sipil / Volume 6, No. 3 - 2011 ISSN 1978 - 5658.

Ammarapala V. 2013. Selection of Weigh Station Locations in Thailand Using The Analytic Hierarchy Process. Journal of Slongkanakarin Journal Science and Technology 35 (1), 81-90, Thailand : Songkla University.

Coulter ED. 2006. The Analytic Hierarchy Process: A Tutorial for Use in Prioritizing Forest Road Investments to Minimize Environmental Effects. International Journal of Forest Engineering Volume 17, Number 2, Montana, United States of America (USA) : University of Montana.

Dalalah D. 2010. Application of the Analytic Hierarchy Process (AHP) in Multi-Criteria Analysis of the Selection of Cranes. Jordan Journal of Mechanical and Industrial Engineering Volume 4, Number 5, Ar Ramtha, Jordan : Jordan University of Science and Technology.

Hadi, AFP. 2009. Metode Analitycal Hierarchy Process untuk Menentukan Prioritas Penanganan Jalan di Wilayah Balai Pemeliharaan Jalan Mojokerto. Jurnal APLIKASI : Media Informasi \& Komunikasi Teknik 
Sipil Terkini / FTSP ITS Volume 6 Nomor 1 - Februari 2009 : ISSN. 1907-753X.

Hidayatullah R. 2009. Penentuan Urutan Prioritas Pemeliharaan Jalan Di Kota Bima, Institut Teknologi Surabaya, Surabaya.

Hotrin R. 2011. Analisis Prioritas Penanganan Jaringan Jalan Strategis Terhadap Pengembangan Wilayah di Kabupaten Humbang Hasundutan, Universitas Sumatera Utara, Medan.

Ishizaka A, Labib A. 2011. Review of the main developments in the Analytic Hierarchy Process. Journal Expert Systems with Applications, 38(11), 14336-14345, Portsmouth, United Kingdom (UK) : University of Portsmouth.

Jamli A. 2003. Penerapan AHP Dalam Penentuan Prioritas Pembangunan : Kasus Jawa Timur dan Jawa Tengah, Malang.

Junaidi A. 2012. Implementasi Metode Entropi Dan Electre II Untuk Menentukan Prioritas Pembangunan Kembali Jembatan Yang Rusak Akibat Bencana Banjir (Studi Kasus Di Kabupaten Trenggalek), Institut Teknologi Sepuluh November, Surabaya.

Juniardi F. 2013. Manajemen Ruas Jalan dan Skala Prioritas Penanganan Jalan di Kota Sukadana Kabupaten Kayong Utara, Universitas Tanjung Pura, Pontianak.

Kamal M. 2001. Application of the AHP in Project Management. International Journal of Project Management 1927, Dhahran, Saudi Arabia : King Fahd University of Petroleum \& Minerals.

Khorasani M. 2013. Evaluation of Road Safety Performance Based On Analytic Hierarchy Process. International Journal of Innovative
Technology and Exploring Engineering (IJITEE), ISSN: 22783075, Volume-3, Issue-5.

Kumar S. 2009. Analytical Hierarchy Process Applied to Vendor Selection Problem: Small Scale, Medium Scale and Large Scale Industries. Business Intelligence Journal Vol. 2, No. 2.

Kurniasih D. 2005. Model Skala Prioritas Pembangunan Kota Bandung Berbasis Good Governance, Universitas Komputer Indonesia, Bandung.

Lalic B. 2009. Analytical Hierarchy Process As A Tool For Selecting And Evaluating Project. International Journal Simulation Project model 8 (2009) 1, 16-26 ISSN 1726-4529, Novi Sad, Serbia : University Of Novi Sad.

Maskur A. 2002. Analisis Penentuan Sektor Pertanian Prioritas Propinsi Riau Di Era Otonomi Daerah, Program Studi Magister Manajemen Agribisnis Program Pasca Sarjana Institut Pertanian Bogor.

Nigim KA. 2003. An Effective Approach to Infrastructure Reconstuction of Devastated Countries. Ontario Canada : University of Waterloo.

Pemerintah Republik Indonesia. 2004. Undang-undang Republik Indonesia Nomor 38 Tahun 2004 tentang Jalan, Jakarta (ID): Sekretariat Negara.

Pemerintah Republik Indonesia. 2006. Peraturan Pemerintah Nomor 34 Tahun 2006 tentang Jalan, Jakarta (ID): Sekretariat Negara.

Pratiwi AH. 2008. Penentuan Prioritas Pembangunan Pelabuhan Di Kabupaten Mukomuko Dengan Metode Analitical Hierarchy Process, Universitas Islam Sultan Agung, Semarang. 
Putri IDANA. 2011. Penentuan Skala Prioritas Penanganan Jalan Kabupaten di Kabupaten Bangli, Universitas Udayana, Denpasar.

Resosudarmo PB. 2002. Analisa Penentuan Sektor Prioritas Di Kelautan dan Perikanan Indonesia, Universitas Indonesia, Depok.

Saputro DA. 2011. Evaluasi Kondisi Jalan

Dan Pengembangan Prioritas Penanganannya (Studi Kasus di Kecamatan Kepanjen Kabupaten Malang). Jurnal Rekayasa Sipil / Volume 5, No. 2 - 2011 ISSN 1978 -5658 .

Setyono JK. 2009. Penentuan Koridor Jalan Lingkar Di Kecamatan Ungaran Timur Kabupaten Semarang. Jurnal Wahana Teknik Sipil / Volume 14 Nomor 2 Agustus 2009: 1 .

Shiba M. 1995. Analytic Hierarchy Process (AHP)-Based MultiAttribute Benefit Structure Analysis of Road Network Systems in Mountainous Rural Areas of Japan. Journal of Forest Engineering, Volume 7, Number 1, Tsu Japan: Mie University.

Simatupang EJ. 2011. Studi Penentuan Prioritas Peningkatan Ruas Jalan Nasional Di Propinsi Kalimantan Tengah. Seminar Nasional Aplikasi Teknologi Prasarana Wilayah ISBN : 978-979-18342-3-0.

Somamiharja A. 1999. Identifikasi FaktorFaktor Penentu Keberhasilan Budidaya Udang Tambak Guna Menentukan Prioritas Kegiatan Dalam Rangka Menyesuaikan GEMA Protekan 2003, Program Studi Magister Manajemen Agribisnis Program Pasca Sarjana Institut Pertanian Bogor.

50 Syawal A. 2013. Perbandingan Skala Prioritas Penanganan Jalan Di
Kabupaten Bengkayang Antara Metode AHP Dengan Metode Bina Marga. Jurnal Teknik Sipil UNTAN / Volume 13 Nomor 2.

Triantaphyllou E. 1995. Using The Analytic Hierarchy Process For Decision Making In Engineering Applications : Some Challenges. International Journal of Industrial Engineering Vol. 2, No. 1, pp. 3544, Los Angeles, United States of America (USA) : Louisiana State University.

Wijayanto. 2012. Model Skala Prioritas Dalam Implementasi Kebijakan Pembangunan Jalan Ditinjau Dari Persepsi Pemangku Kepentingan (Studi Kasus Jalan Layang Non Tol DKI Jakarta), Universitas Indonesia, Depok.

Yang J, Shi P. 2002. Applying Analytic Hierarchy Process in Firm's Overall Performance Evaluation : A Case Study in China. International Journal Of Business, 7(1), ISSN:1083-4346. 